\title{
Hands on Remote Learning Using a DC Motor Controller
}

\author{
Robert Barsanti \\ The Citadel \\ Ronald Hayne \\ The Citadel \\ Johnston Peeples \\ The Citadel
}

\begin{abstract}
An Electrical and Computer Engineering Laboratory exercise has been included in the junior year fall term to partially bridge the theory to practice gap for multiple basic electrical and computer engineering topics. The laboratory investigates facets of power electronics and computer control for students who have recently been introduced to the theory of transistor bridge circuits for voltage polarity control in their electronics class, and digital pulse width modulation for DC motor speed control in their first computer logic class. After brief study of its specification, students follow a lab sequence to set up and instrument a commercial $H$-bridge to first record polarity and magnitude of output voltages under specified input conditions, and subsequently to observe DC motor response to the same inputs. DC power polarity and averaging through Pulse Width Modulation (PWM), as well as the collateral realities of brushed DC motor noise and logic versus power supply levels become clear to most student for the very first time.
\end{abstract}

Keywords: lab exercise, motor controllers, H-bridge, pulse width modulation, remote learning

\section{INTRODUCTION}

It is well documented that many students are motivated to learn more when a hands-on activity is added to the topic (Kuh, 2008). Additionally, many electrical engineering programs are looking for remote laboratory exercises in the pandemic environment. To achieve these goals the faculty has put together a laboratory exercise to demonstrate the operation of a motor controller that can be accomplished by second or third year students with an Analog Discovery kit (Digilent Corporation 2013; Digilent Corporation 2015) and an inexpensive motor controller (L298, 2021: Seeed Studio, 2010).

For the assessment minded among us, at least three ABET student learning outcomes are addressed in the performance of the lab exercise. Outcome 1: identify, formulate, and solve complex engineering problems by applying principles of engineering, science, and mathematics. Outcome 6: develop and conduct appropriate experimentation, analyze and interpret data, and use engineering judgment to draw conclusions. Outcome 7: acquire and apply new knowledge as needed, using appropriate learning strategies (ABET, 2021). 


\section{THE H-BRIDGE CONTROLLER}

The students begin the exercise by downloading the data sheet for L298 Dual H-Bridge Motor Driver shown in figure 1 (L298, 2021).

The L298 Motor Driver is a dual H-bridge that can provide up to 46 volts and four amps to drive a variety of inductive loads including DC and stepping motors. Motor power and Logic power inputs for both motors are connected to the VMS and $+5 \mathrm{~V}$ terminals of the blue connector at bottom center of figure 1 . The small dark green connectors at bottom right and left accept digital inputs for direction control (I1, I2) and for speed control (EA). Modulated power is output to each motor from the green and red terminals midway along each side of figure 1.

Only one motor is required for this exercise.

\section{FIGURE 1 \\ L298 MOTOR DRIVER}

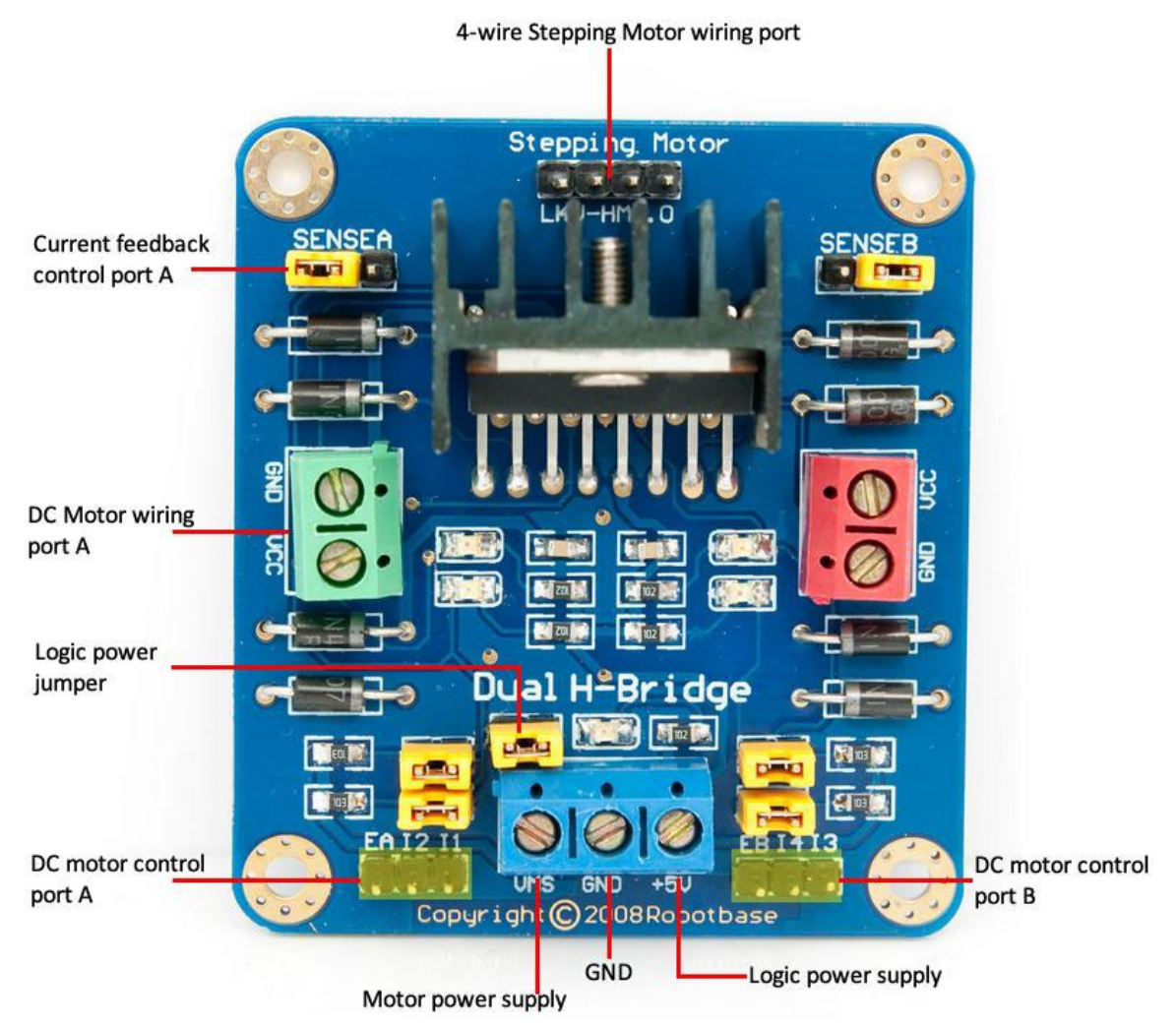

L298, 2021

\section{H-BRIDGE THEORY}

The direction of motion of a DC motor depends on the polarity of the applied voltage. Consider figure 2. If switches S1 and S4 are closed, the VCC supply voltage is connected to the left side of the motor. Conversely, if switches S2 and S3 are closed VCC is connected to the right side, and the motor will turn in the opposite direction. 
FIGURE 2

\section{H-BRIDGE CONCEPT CIRCUIT}

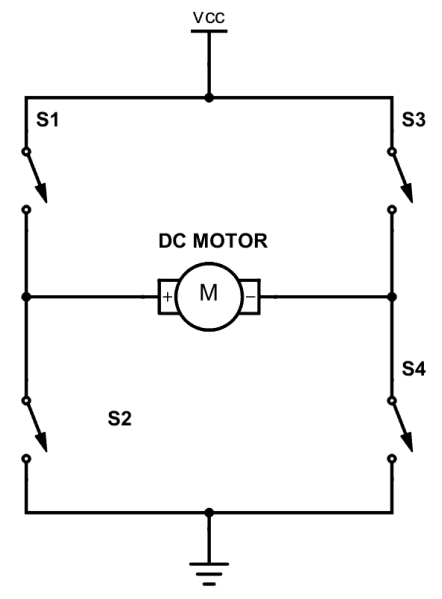

Dahl, O. N., 2018

The simple principle described in figure 2, can be extend to the circuit diagram for the $\mathrm{L} 298 \mathrm{~N}$ dual Hbridge shown in figure 3. Note that it contains two H-bridge circuits A and B. Third year ECE students with experience using transistors and digital logic gates should be able to describe the operation of this circuit. In particular, how the transistors act as switches and how the logic AND gates control the inputs I1, I2, and EA.

FIGURE 3

\section{L298N CIRCUIT DIAGRAM}

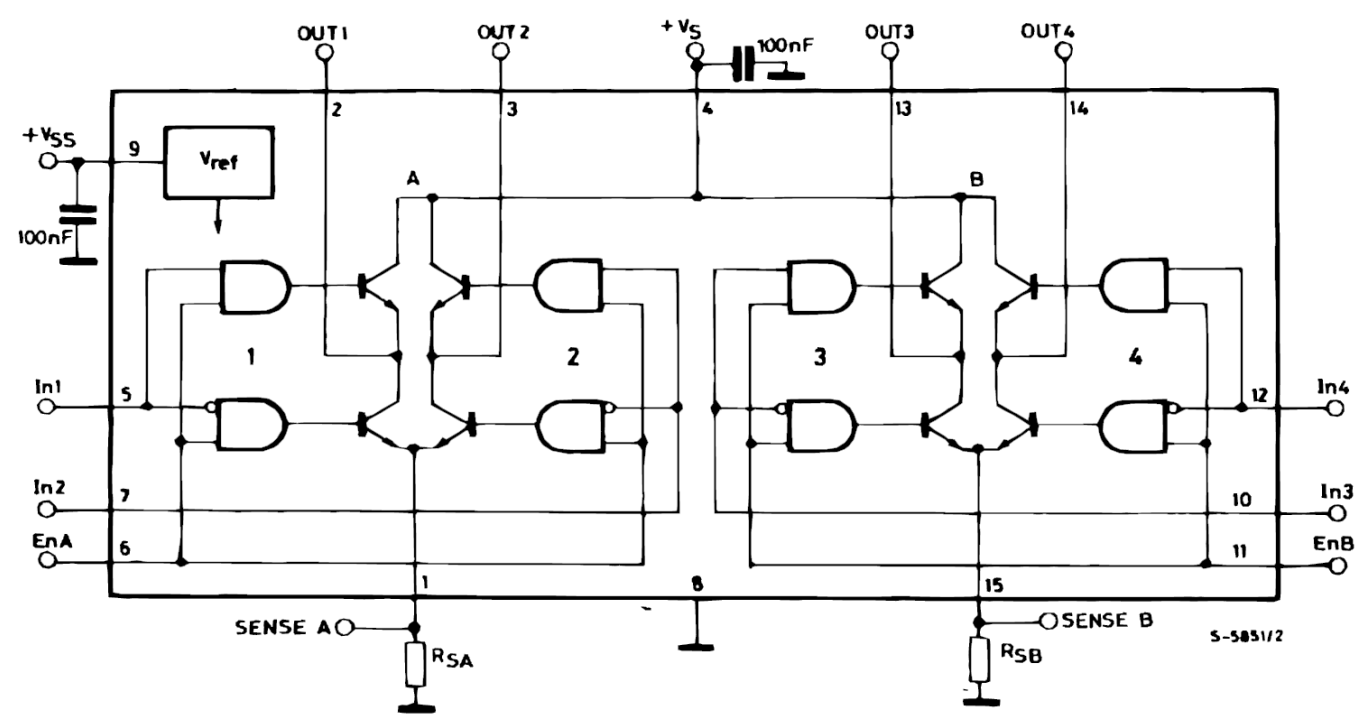

Seeed Studio, 2010

\section{LABORATORY SET-UP}

Students connect the L298, a 6 V DC motor, a $220 \mathrm{ohm}$ resistor, and measuring equipment as shown in figure 4. The $220 \mathrm{ohm}$ resistor is used as a surrogate for the motor when measuring voltages and observing waveforms to eliminate the noise caused by the inexpensive, brushed motor. Analog Discovery 
kits are used to supply the logic power, and measure $\mathrm{V}_{\text {out. }}$. Data collection is designed to illustrate both the operation of the L298 (its $\mathrm{V}_{\text {out }}$ and LED indicators) and the reaction of the motor (speed and direction). The voltage $\mathrm{V}_{\text {out }}$ and the LED indicators are observed using the resistor surrogate, which is then replaced by the motor to observe the effects of the voltages and polarity on motor speed and direction.

Measuring the voltage across the $220 \mathrm{ohm}$ resistor and observing the LED lights on the L298 controller the students complete the truth table shown as table 1.

The truth table indicates that no output voltage is provided to the motor unless the controller is enabled (EA high). Further, positive or negative voltage results when either I1 or I2 is high, therefore controlling the direction of rotation of the DC motor.

\section{FIGURE 4 \\ LAB SET-UP FOR MOTOR CONTROLLER}

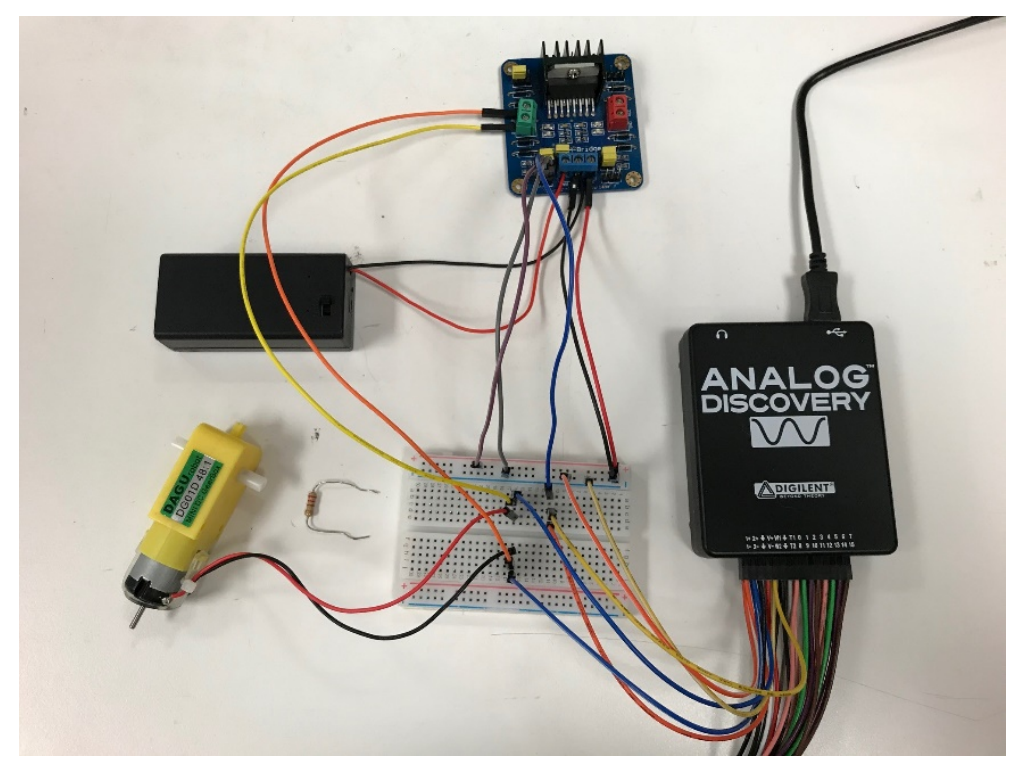

TABLE 1

\section{LOGIC TABLE FOR DC MOTOR CONTROL}

\begin{tabular}{|l|l|l|l|l|l|}
\hline . EA & I 2 & I1 & $V_{\text {out }}$ & LED & Motor Direction \\
\hline \hline L & L & L & $0.00 \mathrm{~V}$ & BOTH & Brake \\
\hline L & L & H & $0.00 \mathrm{~V}$ & RED & Brake \\
\hline L & H & L & $0.00 \mathrm{~V}$ & GREEN & Brake \\
\hline L & H & H & $0.00 \mathrm{~V}$ & NONE & Brake \\
\hline H & L & L & $-6.4 \mathrm{mV}$ & BOTH & Brake \\
\hline H & L & H & $7.57 \mathrm{~V}$ & RED & Clockwise \\
\hline H & H & L & $-7.57 \mathrm{~V}$ & GREEN & Counter-CW \\
\hline H & H & H & $0.8 \mathrm{mV}$ & NONE & Brake \\
\hline
\end{tabular}

\section{PWM Theory}

Pulse width modulation or duty-cycle variation methods are commonly used to control the speed of DC motors. Controlling the on time and off time (duty cycle) of a pulse signal changes the average voltage supplied to the motor without changing the magnitude of the supply. Figure 5 shows a sample PWM waveform. 


\section{FIGURE 5}

PWM SIGNAL

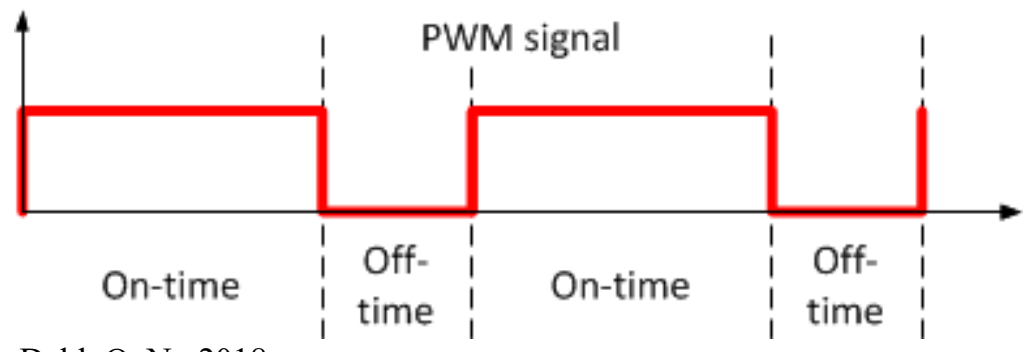

Dahl, O. N., 2018

The students' next procedural step is to set up the circuit for pulse width modulation by connecting the EA input to the waveform generator output of the Analog Discovery.

FIGURE 6

\section{PWM USING ANALOG DISCOVERY WAVEFORM SOFTWARE}

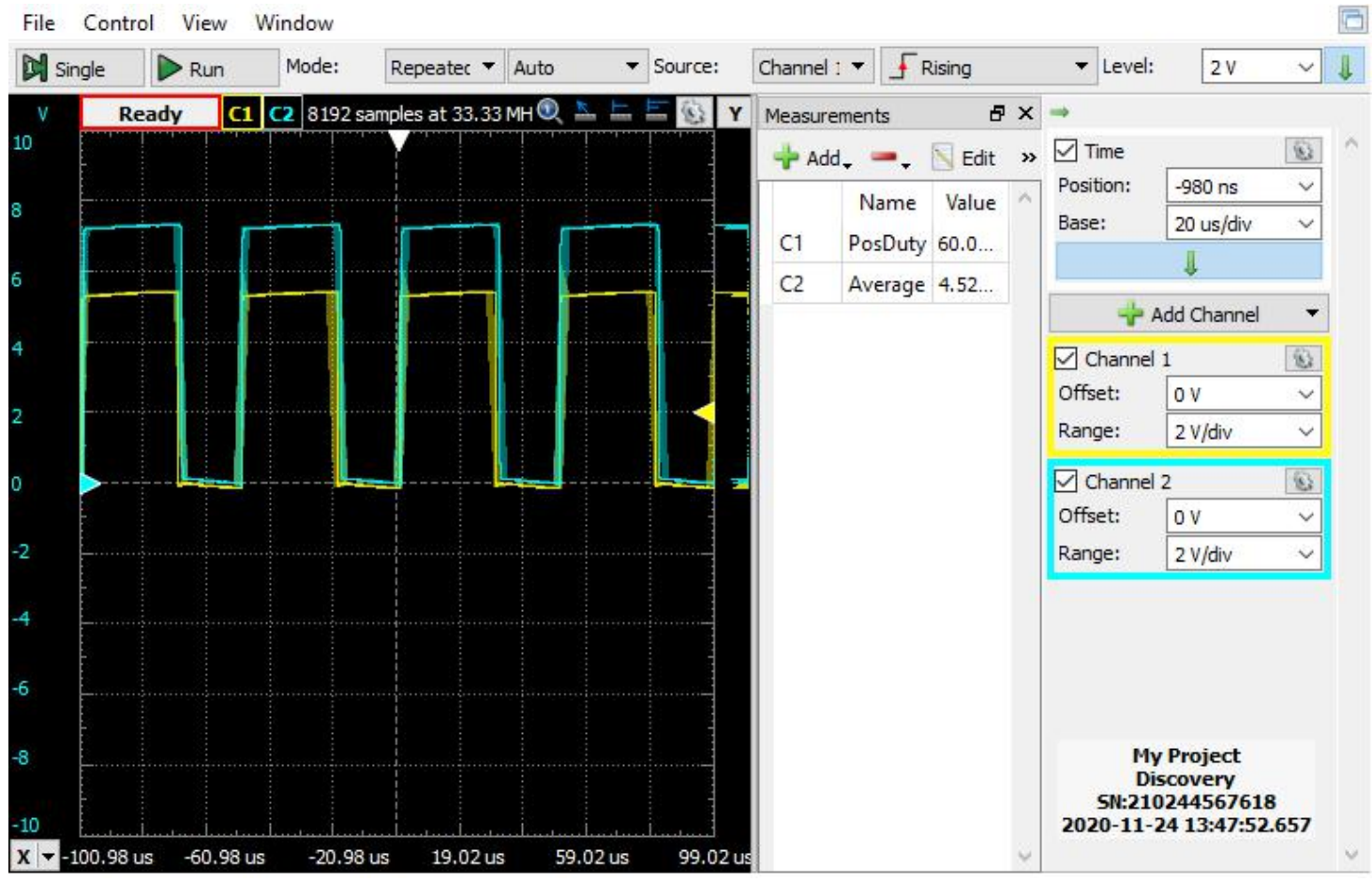

Figure 6 displays a $20 \mathrm{kHz}$ square wave with a $60 \%$ duty cycle. Two channels are employed to observe both the input signal provided to EA and the output voltage across the $220 \mathrm{ohm}$ load. The varying duty cycle at the L298N EA input modulates the 9V DC power to control the speed of the motor. The students record the output voltage for each duty cycle in table 2 .

TABLE 2

PWM DATA

\begin{tabular}{|l||l|l|l|l|l|l|l|}
\hline$D(\%)$ & 20 & 30 & 40 & 50 & 60 & 70 & 80 \\
\hline$V_{\text {out,avg }}(\mathrm{V})$ & 2.21 & 3.04 & 3.85 & 4.67 & 5.48 & 6.29 & 7.10 \\
\hline
\end{tabular}


Students observe that increasing the duty cycle increases the output voltage and thus the speed of the motor, as shown in figure 7.

\section{FIGURE 7 \\ OUTPUT VOLTAGE VS DUTY CYCLE USING TABLE 2 DATA}

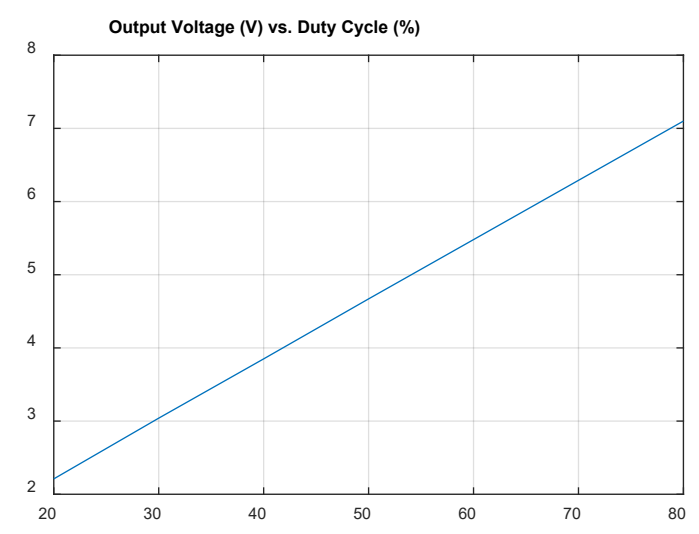

\section{Lab Questions}

The typical laboratory write-up includes the objectives, equipment, procedure, data, results and conclusion section. Additionally, the following questions can be used to induce further thought.

1. What is pulse width modulation?

Pulse width modulation achieves a desired range of DC (average) values for a given waveform by adjusting its duty cycle.

2. What is the relationship between threshold voltage $\mathrm{V}_{\mathrm{ON}}$ and threshold duty cycle $\mathrm{D}_{\mathrm{ON}}$ ?

$\mathrm{V}_{\mathrm{ON}}$ is the input motor voltage that results in a motor output voltage sufficient for the motor to turn. $\mathrm{D}_{\mathrm{ON}}$ is the duty cycle of the enable input that modulates the constant input motor voltage to create the average DC motor output voltage sufficient for the motor to turn.

3. Discuss two ways that the L298 can be used to control the speed and the direction of the DC motor.

The direction of the DC motor is controlled by applying logic High or Low to the inputs I 2 and I1. The speed of the DC motor may be controlled by (a) adjusting the voltage of the power supply to the motor driver board or (b) applying a pulse-width-modulation signal to the motor's Enable line.

\section{EXTENSIONS TO MICROCONTROLLERS}

A follow-on lab uses a PIC32 microcontroller to generate the PWM signals to drive the same H-bridge. Figure 8 depicts the hardware set up, extended to include the Digilent chipKit Wi-Fire microcontroller board (Digilent Corporation, 2017) and the L298. The Wi-FIRE is compatible with the advanced Microchip MPLAB ${ }^{B} X$ IDE and works with all MPLAB ${ }^{\circledR} X$ programmer/debuggers, such as the Microchip PICkit ${ }^{\mathrm{TM}} 3$ or the Digilent ${ }^{\circledR}$ chipKIT PGM. 
FIGURE 8

HARDWARE SET-UP FOR USING PIC 32 TO CREATE THE PWM SIGNAL

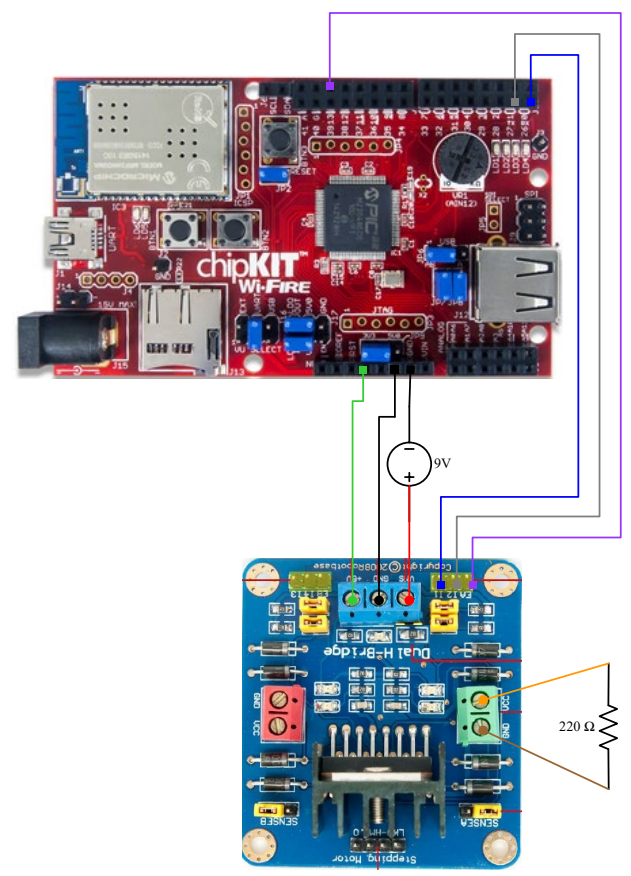

\section{REMOTE LEARNING}

This laboratory exercise is an ideal candidate for remote learning. As itemized in Table 3, the hardware costs for the primary lab (DC motor, L298 and 9V battery) is only \$30, and can be extended to include the microcontroller component for an additional $\$ 80$. Remote learners also need equipment to generate the PWM signals and to record the necessary voltages, which in this case are the Analog Discovery Kit and corresponding WaveForm software.

TABLE 3

\section{PRICE DATA}

\begin{tabular}{|l|l|}
\hline Component & Price \\
\hline L289N H Bridge & 23.50 \\
\hline DC Motor & 6.00 \\
\hline 9Volt battery & 2.00 \\
\hline Digilent chipKit Wi-Fire & 79.00 \\
\hline Analog Discovery Kit (Academic) & 279.00 \\
\hline Waveforms Software & Free \\
\hline Total Cost & $\$ 389.50$ \\
\hline
\end{tabular}

The cost of the Analog Discovery Kit is justified since the program uses these kits for multiple experiments starting with first year introduction to engineering courses; see (Mazzaro, G., Hayne, R., 2016). The program loans these kits to the students for the duration of the semester. 


\section{STUDENT OUTCOMES, ASSESSMENTS, AND RESULTS}

This laboratory exercise requires one lab period, or about two hours, to build and record data. Most students require another two hours to produce a quality laboratory report. Faculty feedback indicates that students who have taken this lab display a better understanding of DC motors topics taught in the required electrical machines course the following spring semester. Faculty also report that students understand and properly use H-bridge motor control in their senior design projects.

Informal student feedback was positive. Students enjoyed the project, and the simplicity of using the Analog Discovery instrument system.

\section{SUMMARY}

The paper reports on a low cost, hands-on project that can be added to an undergraduate analog control or digital control lecture class to improve the student interest and understanding DC motor controller concepts. The paper provides project objectives, procedures and hardware implementation details for a controlling a DC motor driven by a commercial H-bridge controller, and thus allowing students to explore the use of PWM for speed control using low cost instrumentation.

\section{ACKNOWLEDGEMENT}

This paper is a revised version of a paper presented at the 2021 American Society for Engineering Education Southeastern Section conference (Barsanti, Hayne and Peeples, 2021).

\section{REFERENCES}

ABET. (2021). Accreditation Policy and Procedure Manual (APPM) 2020-2021. Retrieved from http://www.abet.org/accreditation

Barsanti, R., Hayne, R., \& Peeples, J. (2021). Hands on Remote Learning using a DC Motor Controller. Proceedings of 2021 ASEE SE Conference.

Dahl, O.N. (2018). What Is an H-Bridge? Retrieved from https://www.build-electronic-circuits.com/hbridge/

Digilent Corporation. (2013). Analog Discovery Technical Reference Manual. Retrieved from https://reference.digilentinc.com/reference/instrumentation/analog-discovery/start

Digilent Corporation. (2015). Waveforms SDK Manual. Retrieved from https://reference.digilentinc.com/reference/instrumentation/analog-discovery-2/specifications

Digilent Corporation. (2017). Wi-FIRE Board Reference Manual. Retrieved from https://digilent.com/reference/_media/reference/microprocessor/wi-fire/wi-fire_rm_revd.pdf

Kuh, G.D. (2008). High Impact Educational Practices: What They Are, Who has Access to Them, and Why they Matter. Association of American Colleges and Universities.

L298. (2021). L298 Dual H Bridge Motor Driver. Retrieved from https://www.robotshop.com/en/seeedstudio-1298-dual-h-bridge-motor-driver.html

Mazzaro, G., \& Hayne, R. (2016). Instructional Demos, In-Class Projects, and Hands-On Homework: Active Learning for Electrical Engineering using the Analog Discovery. Proceedings of 2016 ASEE Annual Conference.

Seeed Studio. (2010). L298 Dual H Bridge Motor Driver Specifications. Retrieved from https://www.robotshop.com/media/files/pdf/datasheet-mot103b1m.pdf

Tantos, A. (n.d.). 1.h Bridges the Basics [PDF Document]. Fdocuments.Net. Retrieved from https://fdocuments.net/reader/full/1h-bridges-the-basics

Zhan, W., Wang, J., \& Vanajakumari, M. (2013). High Impact Activities to Improve Student Learning. Proceedings of $120^{\text {th }}$ ASEE Annual Conference. 